\title{
Beautyberry (Callicarpa arborea) as an Antiparasitic Agent Against Raillietina echinobothrida, an Intestinal Tapeworm
}

\section{P.B. Lalthanpuii, Kholhring Lalchhandama*}

\section{P.B. Lalthanpuii, Kholhring Lalchhandama*}

Department of Life Sciences, Pachhunga University College, Aizawl 796001 , Mizoram, INDIA.

\section{Correspondence}

\section{Kholhring Lalchhandama}

Department of Life Sciences, Pachhunga University College, Aizawl 796001.

Mizoram, INDIA.

Phone no: +91-9436198718

E-mail: chhandama@pucollege.edu.in

History

- Submission Date: 25-10-2019;

- Review completed: 09-11-2019;

- Accepted Date: 03-12-2019.

DOI : 10.5530/pj.2020.12.11

Article Available online http://www.phcogj.com/v12/i1

\section{Copyright}

(C) 2020 Phcogi.Com. This is an openaccess article distributed under the terms of the Creative Commons Attribution 4.0 International license.

\section{ABSTRACT}

Background: The beautyberry (Callicarpa arborea Roxb.) is member of the family Lamiaceae and is native to Asia. It is used in different traditional medicines for the treatment of debilitating ailments including cancer, dermatitis, diabetes mellitus, gastritis, helminthiasis, and pyrexia. A couple of pentacyclic triterpenes and phytosterols have been reported from this plant. Objective: We aimed to investigate the antiparasitic potentials of $C$. arborea bark extract. We used an intestinal tapeworm, Raillietina echinobothrida, for its convenience in handling and established nature as a model helminth parasite. Materials and Methods: The extract of the stem bark was prepared using methanol. Tapeworms were treated in vitro with varying concentrations of the extract. Survival values were statistically analysed. Treated tapeworms were fixed and processed for scanning electron microscopy. Results: $C$. arborea bark extract showed dose-dependent antiparasitic similar to that of albendazole. Scanning electron microscopy revealed damaging effects all over the body of the tapeworm. There was general shrinkage of the tegument on the scolex, neck region and strobila. Microtriches were completely removed throughout the tegument. Suckers and rostellum on the scolex were also deformed. Conclusion: Our data shows that $C$. arborea is a promising source of antiparasitic principles.

Key words: Callicarpa arborea, Scanning electron microscopy, Tapeworm, Tegument.

\section{INTRODUCTION}

Pharmaceutical drugs for helminth infections are on the verge of utter uselessness as a consequence of pervasive drug resistance in all major helminth parasites, especially in livestock animals. Every anthelmintic drug is facing an irrevocable nosedive in terms of effectiveness. ${ }^{1}$ The situation is alarming and prompts for an urgent call to seek new drugs. ${ }^{2,3}$ Global strategic programmes on mass drug administration to eliminate infections are unsatisfactory and not completely sucessful. ${ }^{4}$ As it turns out, helminth infections are now the most prevalent infectious diseases in humans. As of the latest WHO reports, soil-transmitted helminths infect 1.5 billion people, ${ }^{5}$ while schistosomiases alone accounts for another 220 million cases, ${ }^{6}$ thereby surpassing malaria (at 219 million cases), which has always been the predominant infection and leading cause of health crisis.

Callicarpa arborea Roxb. is a perennial mediumsized tree belonging to the family Lamiaceae and is found in China, Nepal, Bhutan, India, Sri Lanka, Bangladesh, and South-East Asian region. In India, Bangladesh and Nepal, the bark is used for the treatment of skin diseases, fever, indigestion, ${ }^{7}$ and boils. ${ }^{8,9}$ In ayurvedic medicine, it is a medication for rheumatism and paralysis. ${ }^{10}$ Among the Adi tribes of northeast India, it is a valuable medication for toothache and scorpion sting. ${ }^{11}$ It is most wellknown as an effective remedy for diabetes mellitus, ${ }^{12}$ and this property is attributed to its ability of enhancing insulin secretion and metabolism of liver glycogen. ${ }^{13}$ The hydro-alcoholic extract of the stem bark was demonstrated as effectively reducing blood-sugar level in streptozotocin-induced diabetic rats. ${ }^{14}$ There are only very few reports on the chemical analysis of the plant. Maslinic acid was isolated from the bark. ${ }^{15}$ This pentacyclic triterpene from other sources has been shown to exhibit antitumor, antidiabetic, antioxidant, cardioprotective, neuroprotective, antiparasitic and growth-stimulating activities. ${ }^{16}$ Chemical detection showed the presence of bauerenol, betulinic acid, and $\beta$-sitosterol in the bark, ${ }^{17}$ and epilupeol, $\beta$-sitosterol, and ursolic acid in the leaves. ${ }^{18}$

In the Mizo traditional medicine, the plant is called hnahkiah and its bark juice is used for the treatment of gastric disorder, dysentery, vomitting, ${ }^{19}$ and haemorrhage ${ }^{20}$ including general cuts and wounds. ${ }^{21}$ Among the Mizo and Andhra Pradesh tribal people, it is consumed twice a day to cure intestinal helminth infection. ${ }^{22}$ So far, this potentially valuable medicinal plant has received no attention on its antiparasitic property. Therefore, it is worthwhile to examine its efficacy and effects against an intestinal tapeworm, R. echinobothrida.

\section{MATERIALS AND METHODS}

\section{Preparation of plant extract}

Callicarpa arborea barks were collected from Aizawl, Mizoram, India. The plant specimen was identified at the Botanical Survey of India, Kolkata, India, and is catalogued (C-01-18) at Pachhunga University College, Aizawl, India. The barks were washed with distilled water and dried under room temperature

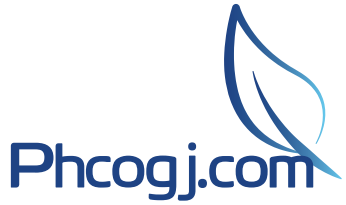

Cite this article: Lalthanpuii PB, Lalchhandama K. Beautyberry (Callicarpa arborea) as an Antiparasitic Agent Against Raillietina echinobothrida, an Intestinal Tapeworm. Pharmacog J. 2020;12(1):66-70. 
$\left(23-25^{\circ} \mathrm{C}\right)$. The dried samples were crushed in an electric blender. Extract was prepared in a 5-L Soxhlet apparatus using methanol as a solvent. The extract was concentrated by recovering the solvent in a vacuum rotary evaporator (Buchi Rotavapor R-215). The final yield was $5.16 \%$. It was then refrigerated at $4^{\circ} \mathrm{C}$ for further use.

\section{Chemicals and drug}

All chemicals were standard analytical grades. Osmium tetroxide, sodium cacodylate and tetramethylsilane were supplied from Merck India, Mumbai. Methanol was procured from SD Fine-Chem Ltd., Mumbai. All other chemicals were obtained from HiMedia Laboratories Pvt. Ltd., Mumbai, India. Albendazole (ZENTEL') was a product of GlaxoSmithKline Pharmaceuticals Ltd., Mumbai, India.

\section{In vitro survival test}

Efficacy of albendazole and C. arborea leaf extracts were assessed by survival test on helminth parasite, Raillietina echinobothrida Mégnin, 1881. Live tapeworms were dissected out and recovered from the intestines of local fowls (Gallus gallus Linnaeus, 1758). They were collected in neutral phosphate-buffered saline (PBS) maintained at $37 \pm 1^{\circ} \mathrm{C}$ in a microbiological incubator. Incremental concentrations, viz. $1.25,2.5,5,10$ and $20 \mathrm{mg} / \mathrm{ml}$, of the plant extract was prepared by dissolving the pre-weighed extract in PBS supplemented with $1 \%$ dimethylsulfoxide (DMSO) in separate culture plates. A set of two tapeworms were introduced into each culture plates. In addition, similar treatment was done for albendazole as a reference drug (with manufactured dosage of $20 \mathrm{mg} / \mathrm{ml}$ ). One set of tapeworms was maintained as control in a medium that contained only PBS with $1 \%$ DMSO. The duration of survival was assessed from the onset of complete paralysis, i.e. when there was complete loss of motor activity upon agitation such as dipping in lukewarm $\mathrm{PBS}\left(45^{\circ} \mathrm{C}\right)$. Each test was performed in triplicates.

All experimental data were normalised against the control and were presented as means plus or minus the standard deviation of the mean $( \pm S D)$. The efficacy of albendazole and the plant extract were compared against the control by Student's $t$-test, and the level of significance was considered when $p$ value was less than 0.05 .

\section{Scanning electron microscopy}

Tapeworms treated with $20 \mathrm{mg} / \mathrm{ml}$ of the plant extract were processed for scanning electron microscopy. After complete paralysis in the culture media, they were washed with PBS and treated with $10 \%$ coldbuffered formaldehyde at $4^{\circ} \mathrm{C}$ for $4 \mathrm{hr}$. The fixative was buffered with 0.1 $\mathrm{M}$ sodium cacodylate ( $\mathrm{pH}$ 7.2.). Secondary fixation was done with $1 \%$ osmium tetroxide $\left(\mathrm{OsO}_{4}\right)$ buffered using the same buffer at $4^{\circ} \mathrm{C}$ for $1 \mathrm{hr}$.
The fixed specimens were dehydrated through increasing concentrations of acetone and finally in pure acetone. They were then treated with tetramethylsilane, $\mathrm{Si}\left(\mathrm{CH}_{3}\right)_{4}$, for $0.25 \mathrm{hr}$ and left to dry in air-drying chamber at $25^{\circ} \mathrm{C}$. The different parts were scrupulously selected and were mounted on metal stubs. Then, they were sputter coated with gold in JFC-1100 (JEOL Ltd., Tokyo, Japan) ion sputtering chamber. Finally, they were observed under a scanning electron microscope (JSM-6360, JEOL Ltd., Tokyo, Japan) at an electron accelerating voltage of $20 \mathrm{kV}$.

\section{RESULTS}

Analysis of the survival test of R. echinobothrida after treatment with $C$. arborea bark extract and albendazole is presented in Table 1. Untreated tapeworms in the control media thrived well for $74.03 \mathrm{hr}$. Both albendazole and the plant extract were effective at all concentrations tested, i.e. at $1.25,2.5,5,10$ and $20 \mathrm{mg} / \mathrm{ml}$, and showed concentrationdependent activity (Figure 1). Albendazole was more active than the plant extract. It took $23.76 \pm 1.93,20.24 \pm 0.58,16.30 \pm 0.66,12.15 \pm$ 0.61 , and $4.39 \pm 0.88 \mathrm{hr}$ respectively to completely kill the tapeworms. $C$. arborea bark extract took longer time, taking $68.28 \pm 2.03,61.68 \pm 1.72$, $43.19 \pm 1.71,35.36 \pm 2.23$, and $25.70 \pm 2.36 \mathrm{hr}$ to kill the tapeworms at the same concentrations.

Figure 2 is an image of $R$. echinobothrida from scanning electron microscopy showing the anterior end of the body. The terminal knoblike scolex and the adjoining body segments (proglottids) of the neck region are visible. The apical depression is the rostellum which showed complete collapse and folding into a creased lip-like structure. Just behind the rostellum are two rounded suckers. Both the suckers are also wrinkled and lost the otherwise smooth contour. The tegument on the scolex and neck is entirely crumpled indicating severe body contraction due to destruction of the tegumental and muscle layers. A close-up view of the upper sucker is shown in Figure 3. There are no signs of the spines and their attachment region along the rim of the circular sucker is left barren. The central and surrounding teguments are constricted and distorted.

The main body (strobila) of the tapeworm consists of a chain of body segments. Toward the neck region are immature and developing segments (Figure 4). The body segments are thin along the transverse loop of the body. The transverse borders of the segments are entirely distorted by irregular creases. A magnification of the same body part reveals total loss of hairy microtriches, indicating complete destruction of the absorptive and sensory organs (Figure 5). Mature body segments are shown in Figure 6. All the body segments show massive shrinkage due to contraction of the tegument. No intact microtriches could be identified implying that they are completely removed (Figure 7).

\section{Table 1: Efficacy of albendazole and an extract of $C$. arborea bark on the tapeworm $R$. echinobothrida in normalised values with respect to control.}

\begin{tabular}{|c|c|c|c|c|}
\hline Media & Dose $(\mathrm{mg} / \mathrm{ml})$ & Normalised survival time in $\mathrm{hr}( \pm \mathrm{SD})$ & $\mathrm{t}$ value & t critical value \\
\hline Control & 0 & $100.00 \pm 2.56$ & - & - \\
\hline \multirow[t]{6}{*}{ Albendazole } & 1.25 & $023.76 \pm 1.93$ & 58.32 & $2.26^{*}$ \\
\hline & 2.5 & $020.24 \pm 0.58$ & 74.53 & $2.45^{*}$ \\
\hline & 5 & $016.30 \pm 0.66$ & 77.66 & $2.45^{\star}$ \\
\hline & 10 & $012.15 \pm 0.61$ & 81.85 & $2.45^{\star}$ \\
\hline & 20 & $004.39 \pm 0.88$ & 86.57 & $2.45^{*}$ \\
\hline & 1.25 & $068.28 \pm 2.03$ & 23.04 & $2.23^{*}$ \\
\hline \multirow[t]{4}{*}{ Callicarpa arborea bark extract } & 2.5 & $061.68 \pm 1.72$ & 30.46 & $2.26^{*}$ \\
\hline & 5 & $043.19 \pm 1.71$ & 45.26 & $2.26^{*}$ \\
\hline & 10 & $035.36 \pm 2.23$ & 46.66 & $2.23^{\star}$ \\
\hline & 20 & $025.70 \pm 2.36$ & 52.29 & $2.23^{\star}$ \\
\hline
\end{tabular}

*Significantly different at $p<0.05$ in comparison with control (0 treatment) group; $n=6$. 


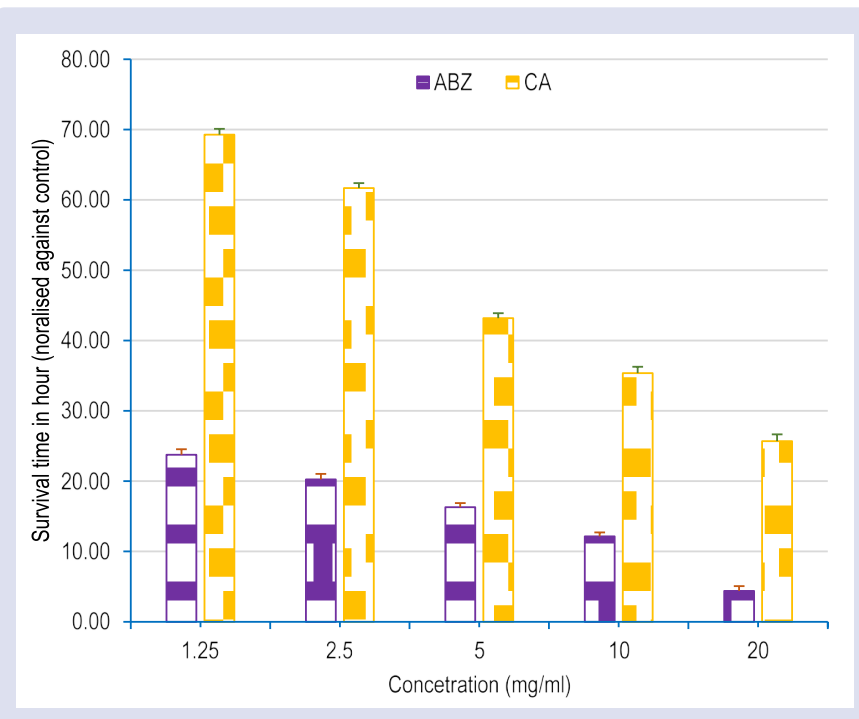

Figure 1: Graph showing the concentration-dependent activity of albendazole (ABZ) and C. arborea extract (CA) against $R$. echinobothrida.

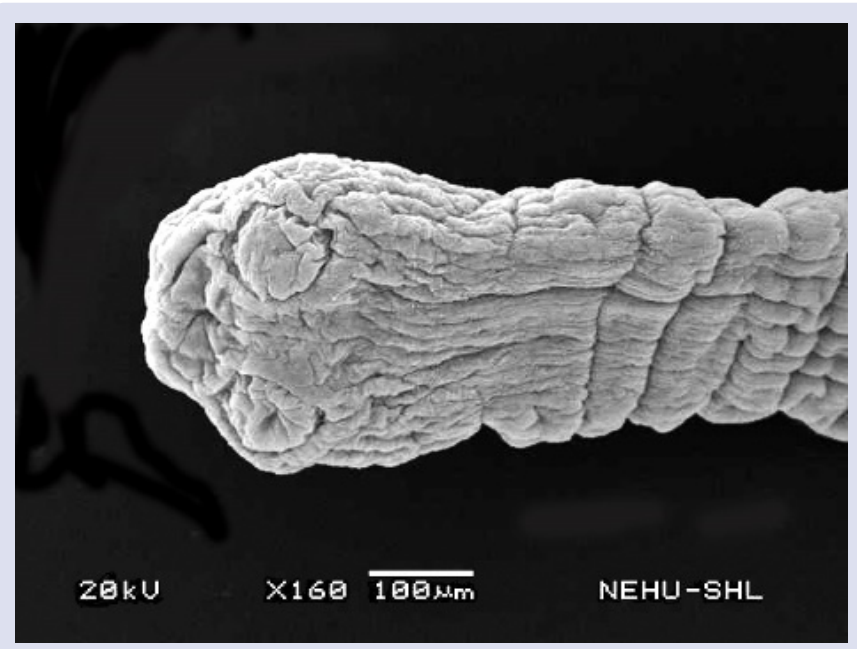

Figure 2: Scanning electron microscopy of R. echinobothrida treated with C. arborea bark extract. Anterior portion of the tapeworm shows an apical rostellum and two suckers in behind. The neck portion with immature body segments is also visible.

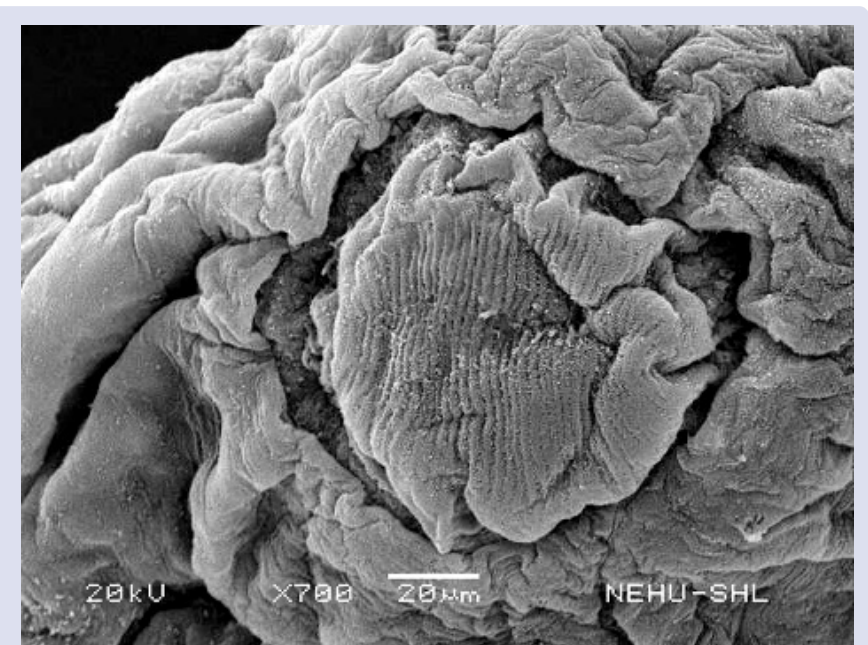

Figure 3: Magnification of the upper sucker of R. echinobothrida scolex exposing tegumental shrinkage and loss of spines.

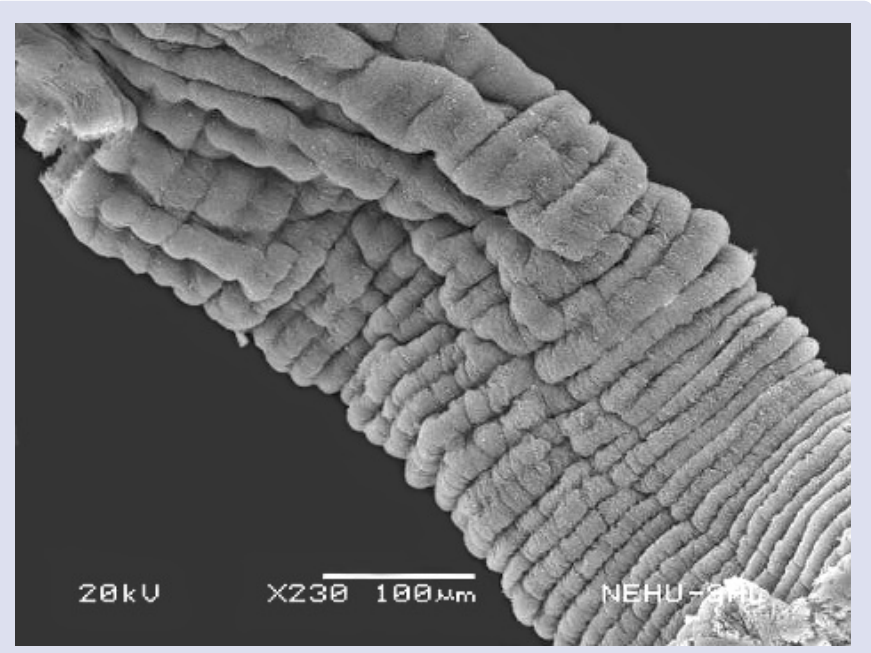

Figure 4: The neck region of $R$. echinobothrida showing a series of creased immature body segments.

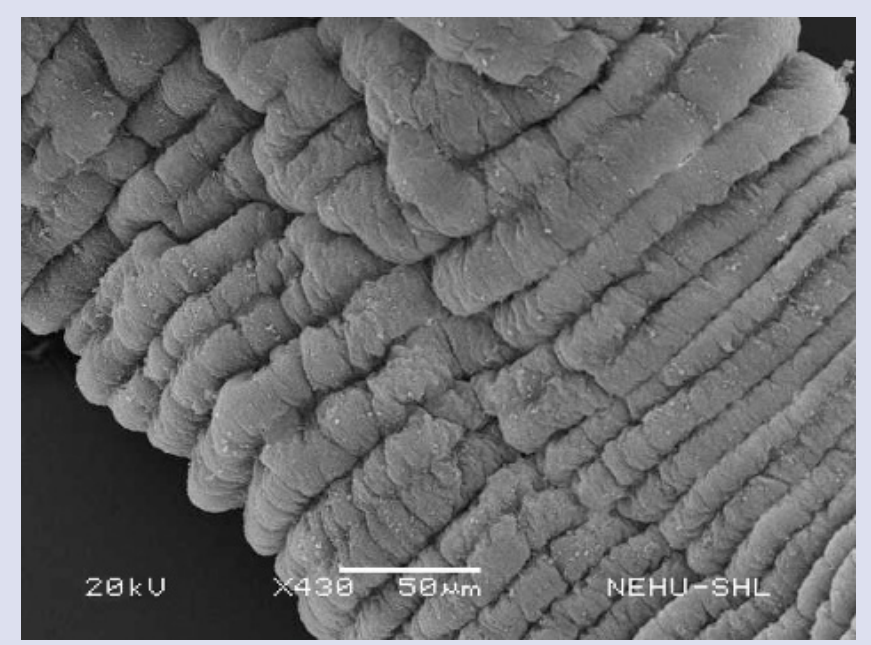

Figure 5: The body segments of $R$. echinobothrida indicating complete loss of microtriches.

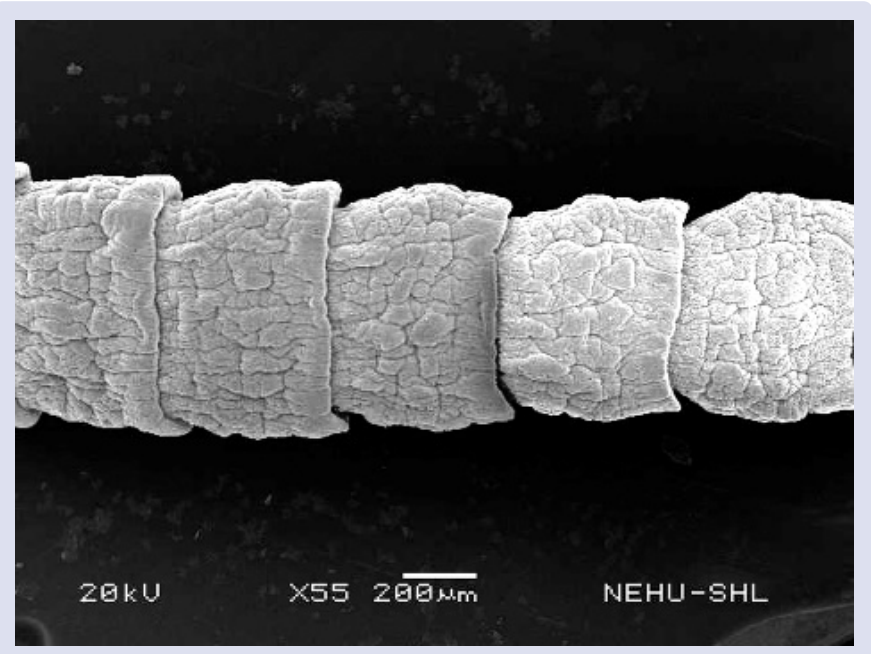

Figure 6: The mature body segments of $R$. echinobothrida exhibiting severe shrinkage. 


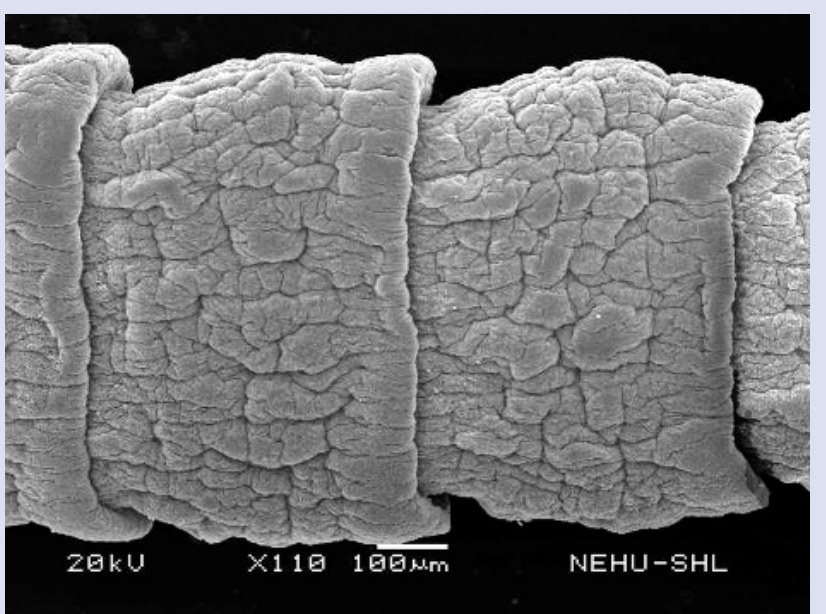

Figure 7: A close-up view of mature body segments of R. echinobothrida revealing complete loss of microtriches.

\section{DISCUSSION}

Tapeworms are unique helminths in that they have rather simple anatomical architecture being bereft of nervous and digestive systems. Their most elaborate features are in fact the external body surface called tegument. Throughout the body the tegument is overlaid with short and slender hair-like filaments called microtriches (literally meaning "minute hairs" from the Greek words mikro meaning small and thrix meaning hair). These microtriches are the direct absorptive and sensory organs, and as such they are the primary route of entry of nutrients and drugs. Anthelmintic drugs act on the tapeworm by passively diffusing through the microtriches and the underlying tegument and internal sub-tegument. Thus, their effects are most directly noted as structural damages in these organs. ${ }^{23,24}$ The only areas of the tegument not entirely covered by microtriches are the rims of suckers (spines) and rostellum (hooks) on the head part, the scolex. These spines and hooks are special parasitic adaptations for anchoring on the tissue surfaces, such as intestinal lumen, of the hosts. Anthelmintic drugs also target these organs and normally cause their breakdown. ${ }^{25}$

The fine morphological structure of $R$. echinobothrida and related species is well understood. ${ }^{26,27}$ In this study, we found that $C$. aroborea extract was evidently effective on the $R$. echinobothrida with dosedependent activity as that of albendazole. The antiparasitic activity was further substantiated by structural damages on the fine body surface. Extensive alterations such as tegumental shrinkage, destruction of the spines and rostellum, and removal of microtriches were clearly the signature effects of an antiparasitic agent.

As broad-spectrum anthelmintics, benzimidazoles are the most versatile and widely used treatment of helminth infections. Their effects and mode of actions are also well understood. Among the most common benzimidazoles, albendazole and flubendazole are demonstrated to cause eruption of swellings or blebs on the tegument, distortion of the entire rostellum, obliteration of the microtriches, and formation of abnormal vesicles on the human tapeworm, Echinococcus granulosus..$^{28}$ A combination therapy of albendazole and praziquantel upon E. granulosus and Mesocestoides corti resulted in deformation of the suckers including dislocation of the spines, and severe disintegration of the tegument accompanied by erosion of microtriches. ${ }^{29,30}$

Albendazole alone caused severe shrinkage and tegumental collapse in R. echinobothrida ${ }^{31}$ Suckers were most noticeably destroyed on the scolex while the rostellum remained largely unaffected. In the present study, it is remarkable that both the suckers and rostellum are equally impaired. Another important observation is that efficacious drugs like praziquantel do not affect the scolex and the neck region of cestodes, implying that they are active as paralytic drugs but not as cestocidal (killing) drugs. ${ }^{32}$ In contrast, we noted that C. arborea bark extract affected indiscriminately the entire body parts on $R$. echinobothrida. This observation indicates that the plant extract has different mode of action and posits the rationale for its potential use in anthelmintic development.

\section{CONCLUSION}

Following its traditional usage, $C$. arborea bark extract was tested on the tapeworm R. echinobothrida and showed dose-dependent antiparasitic activity as that of albendazole. Scanning electron microscopy revealed structural damages on the tapeworm that indicate antiparasitic effects. There was general shrinkage and constriction throughout the body. The scolex with its suckers and rostellum is completely deformed accompanied by loss of rostellar hooks and sucker spines. The body segments were all wrinkled with their microtriches entirely removed. These findings indicate the antiparasitic efficacy and activity of $C$. arborea and warrant further studies on the plant's bioactive compounds and their mode of action.

\section{CONFLICTS OF INTEREST}

None declared.

\section{ACKNOWLEDGEMENT}

The study is funded by Science and Engineering Research Board (SERB), Government of India (EMR/2016/004053). PBL is a Senior Research Fellow under the project.

\section{REFERENCES}

1. Moser W, Schindler C, Keiser J. Drug combinations against soil-transmitted helminth infections. Advances in Parasitology. 2019;103:91-115.

2. Becker SL, Liwanag HJ, Snyder JS, Akogun O, Belizario JrV, Freeman MC, et al Toward the 2020 goal of soil-transmitted helminthiasis control and elimination. PLoS Neglected Tropical Diseases. 2018;12:e0006606.

3. Schulz JD, Moser W, Hürlimann E, Keiser J. Preventive chemotherapy in the fight against soil-transmitted helminthiasis: achievements and limitations. Trends in Parasitology. 2018;34(7):590-602

4. Jourdan PM, Lamberton PH, Fenwick A, Addiss DG. Soil-transmitted helminth infections. The Lancet. 2018;391(10117):252-65.

5. WHO. Soil-transmitted helminth infections. World Health Organization Fact Sheet. Geneva, World Health Organization, 2019.

6. WHO. Schistosomiasis. World Health Organization Fact Sheet. Geneva, World Health Organization, 2019.

7. Jones WP, Kinghorn AD. Biologically active natural products of the genus Callicarpa. Current Bioactive Compounds. 2008;4(1):15-32.

8. Manandhar NP. Ethnobotanical note on folk lore remedies of Baglung district Nepal. Contributions to Nepalese Studies. 1993;20(2):183-96.

9. Das T, Mishra SB, Saha D, Agarwal S. Ethnobotanical survey of medicinal plants used by ethnic and rural people in Eastern Sikkim Himalayan region. African Journal of Basic \& Applied Sciences. 2012;4(1):16-20.

10. Aziz N, Gilani AH, Rindh MA. Kushta(s): unique herbo-mineral preparations used in South Asian traditional medicine. Medical Hypotheses. 2002;59(4):468-72.

11. Srivastava RC. Traditional knowledge of Adi tribe of Arunachal Pradesh on plants. Indian Journal of Traditional Knowledge. 2009;8(2):146-53.

12. Tag $H$, Kalita $P$, Dwivedi $P$, Das AK, Namsa ND. Herbal medicines used in the treatment of diabetes mellitus in Arunachal Himalaya, northeast, India. Journal of Ethnopharmacology. 2012;141(3):786-95.

13. El-Tantawy WH, Temraz A. Management of diabetes using herbal extracts Archives of Physiology and Biochemistry. 2018;124(5):383-9.

14. Junejo JA, Rudrapal M, Nainwal LM, Zaman K. Antidiabetic activity of hydroalcoholic stem bark extract of Callicarpa arborea Roxb. with antioxidant potential in diabetic rats. Biomedicine \& Pharmacotherapy. 2017;95:84-94.

15. Anjaneyulu AS, Lakshminarayana $V$, Row LR. Isolation of maslinic acid from Callicarpa arborea Roxb. Current Science. 1977;46:667-8.

16. Lozano-Mena G, Sánchez-González M, Juan ME, Planas JM. Maslinic acid, a natural phytoalexin-type triterpene from olives-a promising nutraceutical? Molecules. 2014;19(8):11538-59. 
17. Sen M, Pal BC. Chemical investigation of the bark of Calicarpa arborea (Verbenaceae). Journal of Indian Chemical Society 1974;51:903.

18. Sen M, Pal BC. Chemical investigation of the leaves of Calicarpa arborea (Verbenaceae). Journal of Indian Chemical Society 1978;55:744-5.

19. Lalfakzuala $R$, Kayang $H$, Lalramnghinglova $H$. Ethnobotanical usages of plants in western Mizoram. Indian Journal of Traditional Knowledge. 2007;6(3):486-93.

20. Rai PK, Lalramnghinglova $\mathrm{H}$. Ethnomedicinal plant resources of Mizoram, India: Implication of traditional knowledge in health care system. Ethnobotanical Leaflets. 2010;14:274-305.

21. Bhardwaj S, Gakhar SK. Ethnomedicinal plants used by the tribals of Mizoram to cure cuts \& wounds. Indian Journal of Traditional Knowledge. 2005;5(1):75-80.

22. Rao JK, Seetharami TV, Kumar OA. Ethnobotany of stem bark of certain plants of Visakhapatnam district, Andhra Pradesh. Current Botany. 2011;2(5):1-6.

23. Rana AK, Misra-Bhattacharya S. Current drug targets for helminthic diseases. Parasitology Research. 2013;112(5):1819-31.

24. Taman A, Azab M. Present-day anthelmintics and perspectives on future new targets. Parasitology Research. 2014;113(7):2425-33.

25. Roy B, Lalchhandama K, Dutta B. Scanning electron microscopic observations on the in vitro anthelmintic effects of Millettia pachycarpa on Raillietina echinobothrida. Pharmacognosy Magazine. 2008;4(13):20-6.
26. Bâ CT, SeneT, Marchand B. Scanning electron microscope examination of scalelike spines on the rostellumm of five Davaineinae (Cestoda, Cyclophyllidea). Parasite. 1995;2(1):63-7.

27. Lalchhandama K. On the structure of Raillietina echinobothrida, the tapeworm of domestic fowl. Science Vision. 2009;4:174-82.

28. Elissondo M, Dopchiz M, Ceballos L, Alvarez L, Bruni SS, Lanusse C, Denegri G. In vitro effects of flubendazole on Echinococcus granulosus protoscoleces. Parasitology Research. 2006;98(4):317-23.

29. Urrea-Paris MA, Moreno MJ, Casado N, Rodriguez-Caabeiro F. In vitro effect of praziquantel and albendazole combination therapy on the larval stage of Echinococcus granulosus. Parasitology Research. 2000;86(12):957-64

30. Markoski MM, Trindade ES, Cabrera G, Laschuk A, Galanti N, Zaha A, et al. Praziquantel and albendazole damaging action on in vitro developing Mesocestoides corti (Platyhelminthes: Cestoda). Parasitology International. 2006;55(1):51-61.

31. Lalchhandama K. In vitro effects of albendazole on Raillietina echinobothrida, the cestode of chicken, Gallus domesticus. Journal of Young Pharmacists. 2010;2(4):374-8.

32. Chai JY. Praziquantel treatment in trematode and cestode infections: an update. Infection \& Chemotherapy. 2013:45(1):32-43.

\section{GRAPHICAL ABSTRACT}

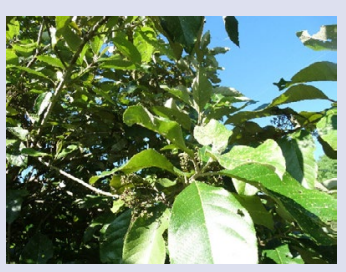

Beautyberry
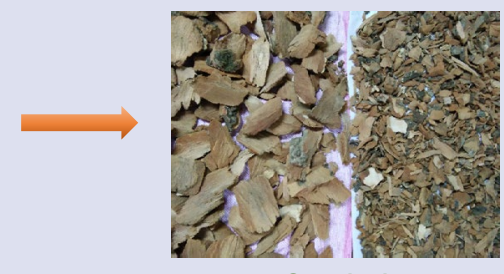

Stem bark

$\checkmark$

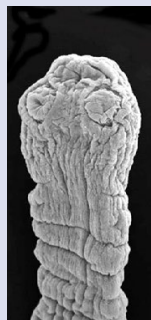

Scanning electron microscopy

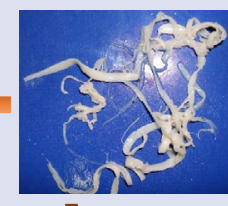

Tapeworms

\section{ABOUT AUTHORS}
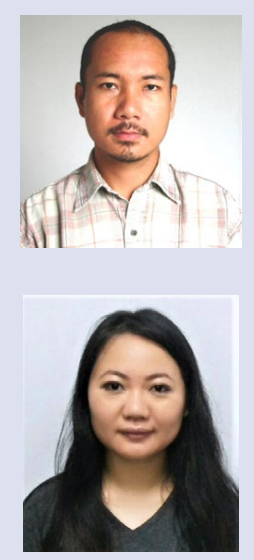

Kholhring Lalchhandama: He graduated in zoology from North Eastern Hill University and earned his doctorate from Assam University. He is currently an Associate Professor and Head of the Department of Life Sciences at Pachhunga University College, Aizawl, India.

P.B. Lalthanpuii: She is a graduate in zoology from North Eastern Hill University and is currently a Senior Research Fellow in the Department of Life Sciences at Pachhunga University College, Aizawl, India.

Cite this article: Lalthanpuii PB, Lalchhandama K. Beautyberry (Callicarpa arborea) as an Antiparasitic Agent Against Raillietina echinobothrida, an Intestinal Tapeworm. Pharmacog J. 2020;12(1):66-70. 